\title{
Contribution of crop model structure, parameters and climate projections to uncertainty in climate change impact assessments
}

Fulu Tao; Reimund P. Rötter; Taru Palosuo; Carlos Gregorio Hernández DíazAmbrona; M. Inés Mínguez; Mikhail A. Semenov; Kurt Christian Kersebaum; Claas Nendel; Xenia Specka; Holger Hoffmann; Frank Ewert; Anaelle Dambreville; Pierre Martre; Lucía Rodríguez; Margarita Ruiz-Ramos; Thomas Gaiser; Jukka G. Höhn; Tapio Salo; Roberto Ferrise; Marco Bindi; Davide Cammarano; Alan H. Schulman

Abstract

Climate change impact assessments are plagued with uncertainties from many sources, such as climate projections or the inadequacies in structure and parameters of the impact model. Previous studies tried to account for the uncertainty from one or two of these. Here, we developed a triple-ensemble probabilistic assessment using seven crop models, multiple sets of model parameters and eight contrasting climate projections together to comprehensively account for uncertainties from these three important sources. We demonstrated the approach in assessing climate change impact on barley growth and yield at Jokioinen, Finland in the Boreal climatic zone and Lleida, Spain in the Mediterranean climatic zone, for the 2050s. We further quantified and compared the contribution of crop model structure, crop model parameters and climate projections to the total variance of ensemble output using Analysis of Variance (ANOVA). Based on the triple-ensemble probabilistic assessment, the median of simulated yield change was $-4 \%$ and $+16 \%$, and the probability of decreasing yield was $63 \%$ and $31 \%$ in the 2050 s, at Jokioinen and 
Lleida, respectively, relative to 1981-2010. The contribution of crop model structure to the total variance of ensemble output was larger than that from downscaled climate projections and model parameters. The relative contribution of crop model parameters and downscaled climate projections to the total variance of ensemble output varied greatly among the seven crop models and between the two sites. The contribution of downscaled climate projections was on average larger than that of crop model parameters. This information on the uncertainty from different sources can be quite useful for model users to decide where to put the most effort when preparing or choosing models or parameters for impact analyses. We concluded that the triple-ensemble probabilistic approach that accounts for the uncertainties from multiple important sources provide more comprehensive information for quantifying uncertainties in climate change impact assessments as compared to the conventional approaches that are deterministic or only account for the uncertainties from one or two of the uncertainty sources.

\section{KEYWORDS}

barley, climate change, Europe, impact, super-ensemble, uncertainty

\section{1 | INTRODUCTION}

Impacts of climate change on future agricultural production and food security have been of key concern because both climate risk and global demand for agricultural production are expected to increase (Godfray et al., 2010). Extensive studies have applied crop models to simulate the potential impacts of climate change on crop growth and productivity from site to global scale (e.g. Asseng et al., 2015; Challinor, Wheeler, Hemming, \& Upadhyaya, 2009; Porter et al., 2014; Rosenzweig et al., 2014; Rötter, Palosuo et al., 2011; Tao, Hayashi, Zhang, Sakamoto, \& Yokozawa, 2008; Tao, Zhang, Liu, \& Yokozawa, 2009; White, Hoogenboom, Kimball, \& Walla, 2011). The simulations were usually driven by climate projections from global climate models (GCMs) downscaled by statistical methods or regional climate models (RCMs) (White et al., 2011). The climate change impact assessments are plagued with uncertainties from many physical, biological and socioeconomic processes involved (Asseng et al., 2013, 2015; Challinor et al., 2009; Lobell \& Burke, 2008; Rötter, 2014; Rötter, Carter, Olesen, \& Porter, 2011; Tao, Yokozawa, \& Zhang, 2009; Tao, Zhang et al., 2009; Wallach, Mearns, Ruane, Rötter, \& Asseng, 2016; Wallach et al., 2017). Among others, uncertainties can originate from greenhouse gas emission scenarios, climate projections of GCMs and their downscaling, crop model structure (different crop models or model equations), input data and parameters (Challinor, Smith, \& Thornton, 2013; Wallach et al., 2017; White et al., 2011). The uncertainties from climate change scenarios and their downscaling have been investigated more often than those from the structure and parameters of crop models (Porter et al., 2014; Rötter, Carter et al., 2011). The uncertainties in structure and parameters of crop models are mainly due to a shortage of high-quality experimental data and inadequacies in understanding the biophysical processes of crop development, growth and grain formation to interactions between genotype, management and environment. In addition, the uncertainties can also be a result of choices crop modellers make when designing their models and deciding their focus, for example which processes to represent, and which level of detail and complexity. The uncertainties in model structure (Asseng et al., 2013, 2015) and parameters (Tao, Yokozawa et al., 2009; Tao, Zhang et al., 2009) of crop models can make a large difference in quantifying the impacts of future climate change and consequently in addressing the adaptation options to climate change. The uncertainties therefore should be as much as possible reduced, managed and quantified to better assess potential climate impact and inform adaptation.

Recent studies have made great progress in dealing with these uncertainties (Asseng et al., 2013, 2015; Challinor et al., 2009; lizumi, Yokozawa, \& Nishimori, 2009; Palosuo et al., 2011; Porter et al., 2014; Rötter, Carter et al., 2011, 2012; Tao et al., 2008; Tao, Yokozawa et al., 2009; Tao, Zhang et al., 2009; Wallach et al., 2016). For example a probabilistic assessment approach was developed for assessing future climate impact on rice productivity and water use in China, based on 20 climate change scenarios and a Monte Carlo technique, to account for the uncertainty from climate projections (Tao et al., 2008). To account for the uncertainty from model parameters in climate impact assessment, those associated with the biophysical parameters in a crop model and the physical parameters in a GCM were estimated for simulating groundnut yield in India (Challinor et al., 2009). The study showed a relatively low crop parameter uncertainty due to observational constraints on the crop parameters. Furthermore, the probability distributions of biophysical parameter values in a crop model were systematically inferred using the Bayesian probability inversion and a Markov Chain Monte Carlo (MCMC) technique together with long-term observed 
data on crop phenology and yield (lizumi et al., 2009; Tao, Zhang et al., 2009). These studies emphasized the importance of accounting for the uncertainties from crop and soil model parameters in climate impact assessment. To account for the uncertainties from both climate projections and crop model parameters, a double-ensemble probabilistic assessment approach was developed for evaluating climate change impact on maize productivity and water use in China (Tao, Yokozawa et al., 2009). The study, using a single crop model, 60 sets of crop model parameters and 10 climate scenarios, suggested that climate projections could generally contribute more uncertainties to climate impact assessment than do crop model parameters.

Recently, uncertainty from model structure has been of key concern (Asseng et al., 2013, 2015; Bassu et al., 2014; CastañedaVera, Leffelaar, Álvaro-Fuentes, Cantero-Martínez, \& Mínguez, 2015; Li et al., 2015; Martre et al., 2015; Palosuo et al., 2011; Pirttioja et al., 2015; Rötter, Carter et al., 2011, 2012; Vanuytrecht \& Thorburn, 2017; Wang et al., 2017). Major international efforts, such as the Modelling European Agriculture with Climate Change for Food Security (MACSUR) project (Ewert et al., 2015) and the Agricultural Model Inter-comparison and Improvement Project (AgMIP) (Rosenzweig et al., 2013), have made great progress in quantifying and reducing uncertainty from model structure in simulating the response of crop yields to climate (e.g. Palosuo et al., 2011; Rötter et al., 2012) and under climate change (e.g. Asseng et al., 2013, 2015; Bassu et al., 2014; Li et al., 2015; Martre et al., 2015; Wang et al., 2017). For example Palosuo et al. (2011) estimated the uncertainty from model structure by comparing eight widely used crop models for winter wheat under current climatic conditions across Europe. A similar study was carried out for barley using nine crop models (Rötter et al., 2012). Subsequently, a considerably larger number of different crop models were compared in simulating climate change impact on crop yields in contrasting climate conditions (Asseng et al., 2013, 2015; Bassu et al., 2014; Li et al., 2015; Martre et al., 2015). The results showed that simulated climate change impacts on crop yield considerably varied across models, owing to differences in model structure and parameter values, and the uncertainty in climate change impact assessment from different crop models was larger than that from the downscaled GCMs (Asseng et al., 2013).

Previous climate change impact studies tried to account for the uncertainties from one or two of the key sources, such as climate projections (e.g. Tao et al., 2008), crop model parameters (e.g. Challinor et al., 2009; lizumi et al., 2009; Tao, Zhang et al., 2009), crop model parameters and climate projections together (Tao, Yokozawa et al., 2009), crop model structure (Palosuo et al., 2011; Rötter et al., 2012), crop model structure and climate projections (Asseng et al., 2013, 2015; Bassu et al., 2014; Li et al., 2015) and crop model structure and parameters (Wallach et al., 2017; Zhang, Tao, \& Zhang, 2017). In this study, we developed a triple-ensemble probabilistic assessment to account for the uncertainties from three important sources together, that is crop model structure, crop model parameter and climate change projection. Our hypothesis is that the triple- ensemble probabilistic approach should provide a better basis for quantifying uncertainties in assessing the impact of climate change than do conventional approaches that are deterministic or only account for the uncertainties from one or two of the sources. The information on the uncertainty from different sources can be quite useful for model users to decide where to put the most effort when preparing or choosing models or parameters for impact analyses. We demonstrated the approach by assessing climate change impact on barley growth and yield at Jokioinen, Finland, in the Boreal climatic zone, and at Lleida, Spain, in the Mediterranean climatic zone, using seven crop models and multiple sets of crop model parameters under eight contrasting climate projections for the 2050s. We further quantified and compared the contributions of crop model structure, crop model parameters and climate projections to the total variance of ensemble output using Analysis of Variance (ANOVA).

\section{MATERIALS AND METHODS}

\section{1 | Study sites}

Two study sites with contrasting climate were chosen to represent the North and South of current agro-climatic conditions for barley cultivation areas in Europe. One is Jokioinen, Finland $\left(60.81^{\circ} \mathrm{N}\right.$, $23.50^{\circ} \mathrm{E}, 104 \mathrm{~m}$ a.s.l.) in northern Europe and the other is Lleida, Spain $\left(41.63^{\circ} \mathrm{N}, 0.60^{\circ} \mathrm{E}, 190 \mathrm{~m}\right.$ a.s.l.) in southern Europe. Jokioinen has a Boreal climate, with an annual mean temperature of $4.6^{\circ} \mathrm{C}$ and total precipitation of $628 \mathrm{~mm}$ for the period 1980-2010. At Jokioinen, spring barley is generally sown in mid-May and harvested at the end of August. Mean temperature and precipitation during the barley growing season were $13.6^{\circ} \mathrm{C}$ and $252 \mathrm{~mm}$ for the period 1980-2010. Lleida has a Mediterranean climate, with annual mean temperature and total precipitation of $15.0^{\circ} \mathrm{C}$ and $341 \mathrm{~mm}$ for the period 1980-2010. At Lleida, winter barley is generally sown in midNovember and harvested at the beginning of July; mean temperature and precipitation during the barley growing season were $11.5^{\circ} \mathrm{C}$ and $227 \mathrm{~mm}$ at Lleida during 1980-2010. In general, the climate at Lleida was much drier than that at Jokioinen.

\subsection{Crop models and data}

An ensemble consisting of seven crop models of varying complexity was applied. General information on the individual crop models is presented in Table 1. The different approaches applied to modelling major processes in the various crop models are summarized in Table S1. All models are process-based and simulate crop growth, development and productivity on a daily time step. There are some differences among models in simulating major processes of crop development, growth, light utilization, photosynthesis and evapotranspiration, biomass accumulation and grain formation (Table S1).

Detailed field experimental data, including soils, tillage, fertilization, phenology, aboveground biomass at anthesis and maturity, yield and agronomic management practices were obtained for two growing seasons at Jokioinen in 2002 and 2009 (Salo et al., 2016) and 
TABLE 1 Information on the seven crop models used in this study

\begin{tabular}{|c|c|c|c|c|}
\hline ID & Crop model & Code & Reference & Documentation \\
\hline 1 & CropSyst 4.15 .04 & CS & $\begin{array}{l}\text { Stockle, Donatelli, and } \\
\text { Nelson (2003) }\end{array}$ & $\begin{array}{l}\text { http://modeling.bsyse.wsu.edu/CS_ } \\
\text { Suite/cropsyst/index.html }\end{array}$ \\
\hline 3 & MCWLA 2.0 & MC & Tao, Zhang et al. (2009) & Request from fulu.tao@luke.fi \\
\hline 4 & MONICA 1.2 .5 & MO & Nendel et al. (2011) & http://monica.agrosystem-models.com \\
\hline 6 & SiriusQuality 2.0 & SQ & Martre et al. (2006) & http://www1.clermont.inra.fr/siriusquality/ \\
\hline 7 & WOFOST 7.1 & WF & $\begin{array}{l}\text { Boogaard and Kroes } \\
\text { (1998) }\end{array}$ & http://www.wofost.wur.nl \\
\hline
\end{tabular}

for three growing seasons at Lleida from 1996 to 1999 (CanteroMartinez, Angas, \& Lampurlanes, 2003). The barley cultivar in the experiment was Annabell at Jokioinen, and Hispanic at Lleida. The soils were Vertic Cambisol with a clay texture at Jokioinen, and Xerofluvent typic with loam texture at Lleida. These experimental data were used for crop model calibration and validation.

Observed daily weather data for solar radiation, minimum and maximum temperature, precipitation, wind speed and air humidity during the period 1980-2010 at the two sites were obtained from the Finnish Meteorological Institute, the Spanish Agencia Estatal de Meteorología (AEMET) and other sources, as detailed in Pirttioja et al. (2015). For future climate, eight contrasting GCMs were selected from the Coupled Model Inter-comparison Project Phase 5 (CMIP5) ensemble (Table 2), driven by the emission scenario of Representative Concentration Pathway (RCP) 8.5 for the period of the 2050s. The eight GCMs were selected based on their climatic sensitivity, characterized by changes in annual mean temperature and precipitation, to preserve the range of uncertainties in CMIP5 (Figure S1, Table S2). This allowed us to quantify uncertainties in climate impact assessment due to uncertainties in the CMIP5 ensemble by conducting fewer simulation experiments (Semenov \& Stratonovitch, 2015).

Daily climate scenarios for the 2050s at the two sites were constructed by applying change factors to observed weather data for the period 1980-2010. For each GCM, the projected changes in monthly maximum and minimum temperature, precipitation and solar radiation between the 2050s and the baseline (1981-2010) were downscaled by applying the LARS-WG weather generator to the two sites, which interpolated the change factors from the neighbouring GCM grids with inverse-distance weighting interpolation (Semenov \& Stratonovitch, 2015). Before applying change factors to observed weather, monthly change factors were linearly interpolated to daily change factors with the monthly change factors being assigned to the middle day of the corresponding month. Finally, by applying daily change factors to the observed daily weather, we constructed a daily local-scale scenario of 31 years for the 2050s from each GCM that was used for crop model simulation. These crop simulations were compared with those using the baseline scenario, that is the observed weather for 1980-2010.

\section{3 | Crop model parameter perturbation and modelling protocol}

For each crop model, the key seven or eight crop model parameters that are closely related to crop growth, development and grain formation were identified by each crop modelling group based on sensitivity analyses or previously gathered experiences on model performance using different sets of parameters (Tao et al., 2016). Based on detailed field trial data on barley response (phenology and yield) to agronomic management practices and environmental conditions at Jokioinen and Lleida, for each crop model the selected key parameters (Table S3) were calibrated using the traditional trial-anderror method. This was done based on 1 year's trial data and then validated against the remaining experimental data. At each site, for each model, with its respective single set of calibrated parameters, the differences between simulated and observed flowering and maturity dates were less than 5 days, and the discrepancies between observed and simulated yield were less than $20 \%$ (Tao et al., 2016). Then, the potential value range for each of the important model parameters was determined by consulting experts and the literature for Jokioinen and Lleida respectively (Table S3). It was difficult to fix these potential parameter ranges with high accuracy, yet, but for the purpose of this study, plausible and approximate parameter ranges were sufficient. The parameter ranges were set somewhat wider to cover the potential variations of the parameters in the foreseeable future, thus they could cover potential changes in future barley cultivar traits to some extent. Next, for each of the most important seven or eight parameters in a crop model, three representative values $\left(V_{1}, V_{2}, V_{3}\right)$ across the range of the parameter values (from $V_{\text {min }}$ to $\left.V_{\text {max }}\right)$, that is the value at the one-sixth point $\left(V_{1}=V_{\min }+\left(V_{\max }-V_{\min }\right) * 1 / 6\right)$, middle point $\left(V_{2}=\left(V_{\min }+V_{\max }\right) / 2\right)$ and five-sixth point $\left(V_{3}=V_{\min }+\left(V_{\max }-V_{\min }\right) * 5 / 6\right)$, were selected. The three representative values for each of the seven or eight crop model parameters were randomly combined, resulting in $3^{n}$ ( $n$ is the number of the selected parameters for a crop model) sets of parameters for each crop model and for Jokioinen and Lleida respectively. Finally, with each crop model, simulations were conducted under the baseline climate (1981-2010) and eight different projected climates for the 2050s, using the single set of calibrated parameters and $3^{n}$ 
TABLE 2 Information on the eight GCMs selected for this study

\begin{tabular}{|c|c|c|c|c|c|}
\hline GCM & Code & Country & Research centre & Grid resolution & Reference \\
\hline ACCESS1-3 & ACCESS & Australia & $\begin{array}{l}\text { The Centre for Australian } \\
\text { Weather and Climate } \\
\text { Research }\end{array}$ & $1.25^{\circ} \times 1.88^{\circ}$ & Rashid, Hirst, and Dix (2013) \\
\hline EC-EARTH & EC-EARTH & Europe & EC-Earth consortium & $1.122^{\circ} \times 1.125^{\circ}$ & Hazeleger et al. (2012) \\
\hline GFDL-CM3 & GFDL & USA & $\begin{array}{l}\text { Geophysical Fluid Dynamics } \\
\text { Laboratory, NOAA }\end{array}$ & $1.99^{\circ} \times 2.48^{\circ}$ & Dunne et al. (2013) \\
\hline HadGEM2-ES & HadGEM & UK & UK Meteorological Office & $1.25^{\circ} \times 1.88^{\circ}$ & Jones et al. (2011) \\
\hline IPSL-CM5A-MR & IPSL & France & Institute Pierre Simon Laplace & $1.26^{\circ} \times 2.50^{\circ}$ & Dufresne et al. (2013) \\
\hline MIROC-ESM & MIROC & Japan & $\begin{array}{l}\text { University of Tokyo, National } \\
\text { Institute for Envir. Studies, } \\
\text { Japan Agency for Marine-Earth } \\
\text { Science \& Technology }\end{array}$ & $2.77^{\circ} \times 2.81^{\circ}$ & Watanabe et al. (2011) \\
\hline
\end{tabular}

sets of perturbed parameters, for Jokioinen and Lleida respectively. The parameter perturbation method was applied to include all possible cases of parameters combinations. However, without assuming any covariance among the parameters, this might lead to a slight overestimation of uncertainty. Other resampling technique such as hypercube could provide more random combinations but could result in loss of some possible parameters combinations when limited sampling times are used.

\subsection{Analyses}

As shown in Figure 1, for each crop model, the simulated yield changes under eight different projected climates between the 2050s and the baseline climate (1981-2010), using the single set of calibrated parameters and $3^{n}$ sets of perturbed parameters, respectively, were first analysed and compared. For each crop model and climate projection combination, the average yield change between the 30 years in the 2050s and the 30 years in the baseline (1981-2010) was calculated in two steps. The yield change between each individual year in the 2050s and its corresponding year in the baseline was first calculated, and then the resultant 30 yield change values were averaged to represent the yield changes between the two periods. Thereafter, we investigated the uncertainties from crop model structure, parameters and climate projections in the climate change impact assessment.

We quantified the uncertainty from model structure by comparing the seven different crop models in simulating yield changes under the eight different climate projections for the 2050s with their single set of calibrated parameters and $3^{n}$ sets of perturbed parameters respectively. The uncertainty from model parameters was quantified by comparing the differences in simulated yield changes for each of the seven crop models using their respective single set of calibrated parameters and $3^{n}$ sets of perturbed parameters under baseline climate conditions and the eight different climate projections for the 2050s. The uncertainty from climate projections was quantified by comparing the differences in simulated yield changes under the eight different climate projections for the 2050s using each of the seven crop models with their single set of calibrated parameters and $3^{n}$ sets of perturbed parameters respectively. Finally, ANOVA was applied to quantify and compare the contribution of crop model structure, crop model parameters and climate projections to the total variance of ensemble output (Figure 1).

The relative contributions of model structure and climate projections to uncertainties were quantified by investigating the simulated yield changes using the seven crop models and eight different climate projections, with their respective single set of calibrated parameters and $3^{n}$ sets of perturbed parameters respectively. For each of the seven crop models, the relative contributions of model parameters and climate projections to uncertainties were quantified by investigating the simulated yield changes using eight different climate projections with their respective $3^{n}$ sets of perturbed parameters. In ANOVA, the total sum of squares $\left(\mathrm{SS}_{\mathrm{T}}\right)$ and the sum of squares (SS) from crop model structure $\left(\mathrm{SS}_{\mathrm{S}}\right)$, crop model parameters $\left(\mathrm{SS}_{\mathrm{P}}\right)$, climate projections $\left(\mathrm{SS}_{\mathrm{C}}\right)$ and error $\left(\mathrm{SS}_{\mathrm{E}}\right)$ were calculated. Then, the share of variance (\%) by $\mathrm{SS}_{\mathrm{S}}, \mathrm{SS}_{\mathrm{P}}, \mathrm{SS}_{\mathrm{C}}$ and $\mathrm{SS}_{\mathrm{E}}$ was calculated as $\mathrm{SS}_{\mathrm{S}} / \mathrm{SS}_{\mathrm{T}} * 100 \%, \mathrm{SS}_{\mathrm{P}} / \mathrm{SS}_{\mathrm{T}} * 100 \%, \mathrm{SS}_{\mathrm{C}} / \mathrm{SS}_{\mathrm{T}} * 100 \%$ and $\mathrm{SS}_{\mathrm{E}} / \mathrm{SS}_{\mathrm{T}} * 100 \%$.

\section{3 | RESULTS}

\section{1 | Projected climate change at the two sites by the eight GCMs}

There were quite large differences among the eight climate conditions projected by the eight GCMs with different model structures (Table 3). Across the eight climate projections, at Jokioinen, during the barley growing period, mean minimum temperature $\left(T_{\min }\right)$ and maximum temperature $\left(T_{\max }\right)$ were projected to increase by 1.5 $4.8^{\circ} \mathrm{C}$ and $1.5-5.2^{\circ} \mathrm{C}$, respectively, during the $2050 \mathrm{~s}$, relative to 1981-2010. Mean precipitation was projected to change by $-2 \%$ to $+13 \%$. Mean solar radiation was projected to change by $-2 \%$ to 


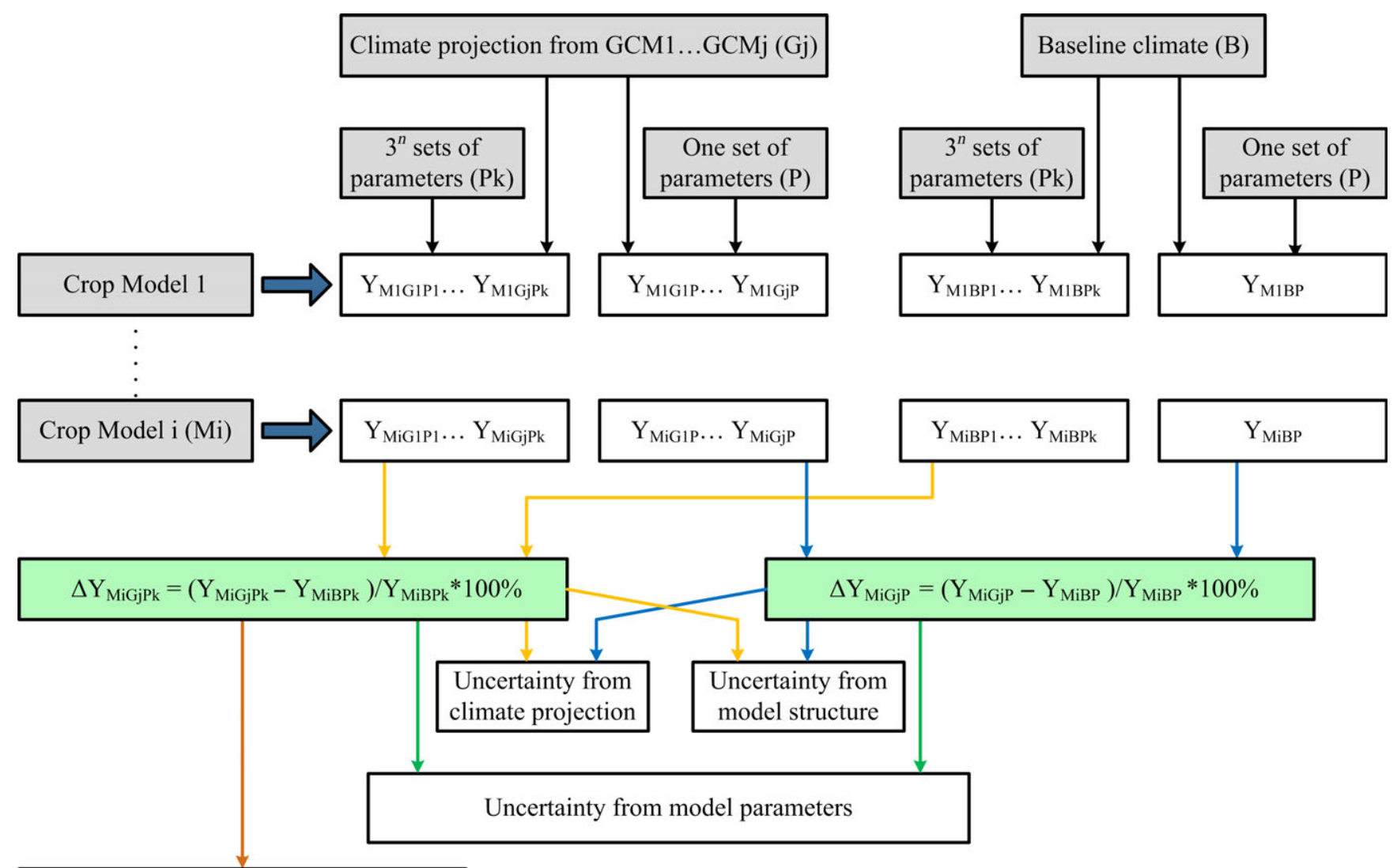

Uncertainty from model structure, model parameters, and climate projection

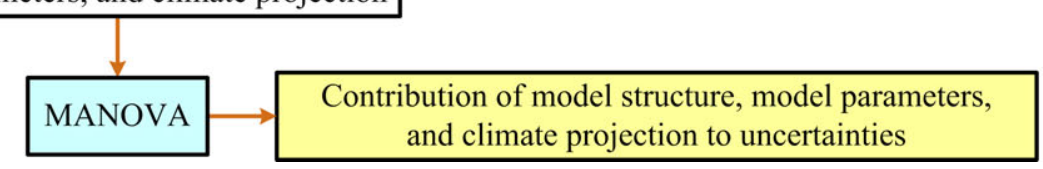

FIGURE 1 Workflow of the study. $Y$ represents simulated yield. $\Delta Y_{\text {MiGjPk }}$ and $\Delta Y_{\text {MiGjpk }}$ were computed based on each individual year between the 2050s and the baseline, then averaged [Colour figure can be viewed at wileyonlinelibrary.com]

$+12 \%$. At Lleida, during the barley growing period, mean $T_{\min }$ and $T_{\max }$ were projected to increase by $1.3-2.6^{\circ} \mathrm{C}$, and $1.3-3.6^{\circ} \mathrm{C}$, respectively, relative to $1981-2010$. Mean precipitation was projected to change by $-27 \%$ to $+15 \%$. Mean solar radiation was projected to change by $-1 \%$ to $+10 \%$ (Table 3 ).

\subsection{Uncertainty from crop model structure}

Using the seven crop models with their respective single set of calibrated model parameters, the simulated yield changes were quite different by the seven crop models for both Jokioinen and Lleida. The median of simulated yield changes in the 2050s ranged from $-34 \%$ to $+8 \%$ at Jokioinen (Table 4 ) and from $-39 \%$ to $+138 \%$ at Lleida (Table 5) across the eight climate projections, relative to 1981-2010. With their respective $3^{n}$ sets of perturbed parameters, the seven crop models also resulted in quite different yield changes at both Jokioinen and Lleida. The median of simulated yield changes in the 2050s ranged from $-24 \%$ to $+7 \%$ at Jokioinen (Table 4 , Figure 2) and from $-19 \%$ to $+75 \%$ at Lleida (Table 5 , Figure 3 ) across the eight climate projections, relative to 1981-2010. The seven models were hardly consistent even in the impact sign of simulated yield change under the same climate projection. The CropSyst projected a large yield decrease, whereas the SiriusQuality projected a yield increase at Jokioinen under most of the climate projections (Table 4). The CropSyst projected a large yield decrease, whereas the HERMES and MONICA projected a large yield increase at Lleida under most of the climate projections (Table 5). The differences in the simulated yield changes could to some extent are ascribed to the different responses of these crop models to the projected climate conditions. For example at Jokioinen, temperature during the barley growing period was projected to increase most by MIROC (Table 3); and as a result, barley yield was projected to decrease by all seven crop models - yet but with quite different magnitudes, under the climate projection (Table 4). At Lleida, precipitation during the barley growing period was projected to increase by EC_EARTH and decrease by the other seven GCMs, decreasing most by GFDL (Table 3). As a result, barley yield was projected to increase by five of the seven crop models under the climate projection by 
TABLE 3 Projected changes in mean maximum temperature ( $\left.T_{\text {max }}\right)$, minimum temperature $\left(T_{\min }\right)$, precipitation and solar radiation during the barley growing period by the eight GCMs at Jokioinen and Lleida for the 2050s, relative to 1981 2010

\begin{tabular}{|c|c|c|c|c|c|c|c|c|}
\hline \multirow[b]{2}{*}{ GCMs } & \multicolumn{4}{|c|}{ Jokioinen } & \multicolumn{4}{|c|}{ Lleida } \\
\hline & $\begin{array}{l}T_{\min } \\
\left({ }^{\circ} \mathrm{C}\right)\end{array}$ & $\begin{array}{l}T_{\max } \\
\left({ }^{\circ} \mathrm{C}\right)\end{array}$ & $\begin{array}{l}\text { Precipitation } \\
\text { (\%) }\end{array}$ & $\begin{array}{l}\text { Solar } \\
\text { radiation } \\
\text { (\%) }\end{array}$ & $\begin{array}{l}T_{\min } \\
\left({ }^{\circ} \mathrm{C}\right)\end{array}$ & $\begin{array}{l}T_{\max } \\
\left({ }^{\circ} \mathrm{C}\right)\end{array}$ & $\begin{array}{l}\text { Precipitation } \\
\text { (\%) }\end{array}$ & $\begin{array}{l}\text { Solar } \\
\text { radiation } \\
(\%)\end{array}$ \\
\hline ACCESS1-3 & 2.6 & 2.6 & 13 & 3 & 2.6 & 2.6 & -18 & 6 \\
\hline EC-EARTH & 2.5 & 2.5 & 10 & 0 & 2.2 & 2.2 & 15 & 0 \\
\hline GFDL-CM3 & 4.1 & 4.2 & 4 & 12 & 2.5 & 3.6 & -27 & 10 \\
\hline GISS-E2-R-CC & 2.5 & 2.4 & 6 & -2 & 1.3 & 1.3 & -1 & -1 \\
\hline HadGEM2-ES & 3.4 & 3.4 & 2 & 4 & 2.1 & 2.7 & -1 & 5 \\
\hline IPSL-CM5A-MR & 3.4 & 3.0 & 2 & 3 & 1.8 & 2.1 & -4 & 0 \\
\hline MIROC-ESM & 4.8 & 5.2 & 9 & 5 & 2.6 & 3.0 & -18 & 10 \\
\hline MPI-ESM-MR & 1.5 & 1.5 & -2 & 1 & 1.4 & 1.6 & -5 & 2 \\
\hline
\end{tabular}

EC_EARTH; and decrease by four of the models under the climate projection by GFDL (Table 5). The large differences between the estimates from different crop models suggest that quite a large uncertainty in climate impact assessments should originate from crop model structure.

\section{3 | Uncertainty from crop model parameters}

At both Jokioinen and Lleida, for each crop model, the simulated yield changes in the 2050s had quite a large range with $3^{n}$ sets of perturbed crop model parameters, particularly for the HERMES, MCWLA and SIMPLACE (Figures 2 and 3). The results showed that crop model parameter perturbations could lead to substantial differences in simulated yield changes under future climate projections, even in the impact sign (Figures 2 and 3). For each crop model, the median of simulated yield changes in the 2050s with their respective $3^{n}$ sets of perturbed model parameters was also quite different from that with their respective single set of calibrated model parameters (Figures 2 and 3, Tables 4 and 5). For example at Jokioinen, the median of simulated yield changes in the 2050s relative to $1981-2010$ by the MCWLA model was $+5 \%$ vs. $-3 \%$ with one versus $3^{n}$ sets of perturbed model parameters, across the eight climate projections (Figure 2, Table 4). For the WOFOST model, this was $-15 \%$ vs. $-9 \%$ respectively. At Lleida, the median of simulated yield changes in the 2050s relative to $1981-2010$ by the MCWLA model was $36 \%$ vs. $26 \%$ with one vs. $3^{n}$ sets of perturbed model parameters, across the eight climate projections (Figure 3 , Table 5). For the WOFOST model, this was $12 \%$ vs. $22 \%$ respectively. The SD ranged from $4 \%$ to $35 \%$ at Jokioinen (Table 4 ) and $3 \%-66 \%$ at Lleida (Table 5) across the seven crop models and eight climate projections. The role of crop model parameter perturbation was also clearly shown by the large differences between the simulated yields with one vs. $3^{n}$ sets of perturbed model parameters under baseline climate conditions at both Jokioinen (Figure 2) and Lleida (Figure 3). The large differences between the estimates using different sets of model parameters suggest that a large uncertainty in climate impact assessments should originate from crop model parameters.

\section{4 | Uncertainty from climate projections}

Due to the very different projected climatic conditions (Table 3), both at Jokioinen (Table 4) and Lleida (Table 5), the simulated yield changes under the eight climate projections were distinct using each crop model with their respective single set of calibrated parameters. The simulated yield changes under the eight projections were also different using each crop model with their respective $3^{n}$ sets of perturbed parameters at Jokioinen (Figure 2, Table 4) and Lleida (Figure 3, Table 5). Finally, the simulated yield changes under the climate projections were different with all the seven crop models with either their single set or $3^{n}$ sets of perturbed parameters at Jokioinen (Figure 4, Table 4) and Lleida (Figure 4, Table 5) respectively. Using a single crop model with its respective single set of calibrated parameters, the SD ranged from $3 \%$ to $20 \%$ at Jokioinen (Table 4) and from $2 \%$ to $64 \%$ at Lleida (Table 5), across the eight climate projections. Using a single crop model with its respective $3^{\text {n }}$ sets of perturbed parameters, the SD ranged from $4 \%$ to $35 \%$ at Jokioinen (Figure 2, Table 4) and from 3\% to $66 \%$ at Lleida (Figure 3 , Table 5), across the eight climate projections. The differences in the simulated yield changes could to some extent be ascribed to the different climate projections from the eight GCMs. For example at Jokioinen, $T_{\max }$ during the barley growing period was projected to increase from $1.5^{\circ} \mathrm{C}$ by MPI to $5.2^{\circ} \mathrm{C}$ by MIROC (Table 3); and as a result, the crop model MCWLA resulted in different yield changes from $-10 \%$ under the climate projection by MIROC to $+15 \%$ under the climate projection by MPI (Table 4). At Lleida, precipitation during the barley growing period was projected to change from $-27 \%$ by GFDL to $+15 \%$ by EC-EARTH (Table 3 ); and as a result, the crop model WOFOST resulted in different yield changes from $-27 \%$ under the climate projection by GFDL to $+80 \%$ under the climate projection by EC-EARTH (Table 5).

Using all the seven crop models with their respective $3^{n}$ sets of perturbed parameters, the probability density function of projected yield changes was quite different for different climate projections (Figure 4). The median of simulated yield changes in the 2050s, relative to 1981-2010, ranged from $-12 \%$ to $+3 \%$ at Jokioinen (Figure $4 a$, Table 4 ) and from $-30 \%$ to $+105 \%$ at Lleida (Figure $4 b$, 


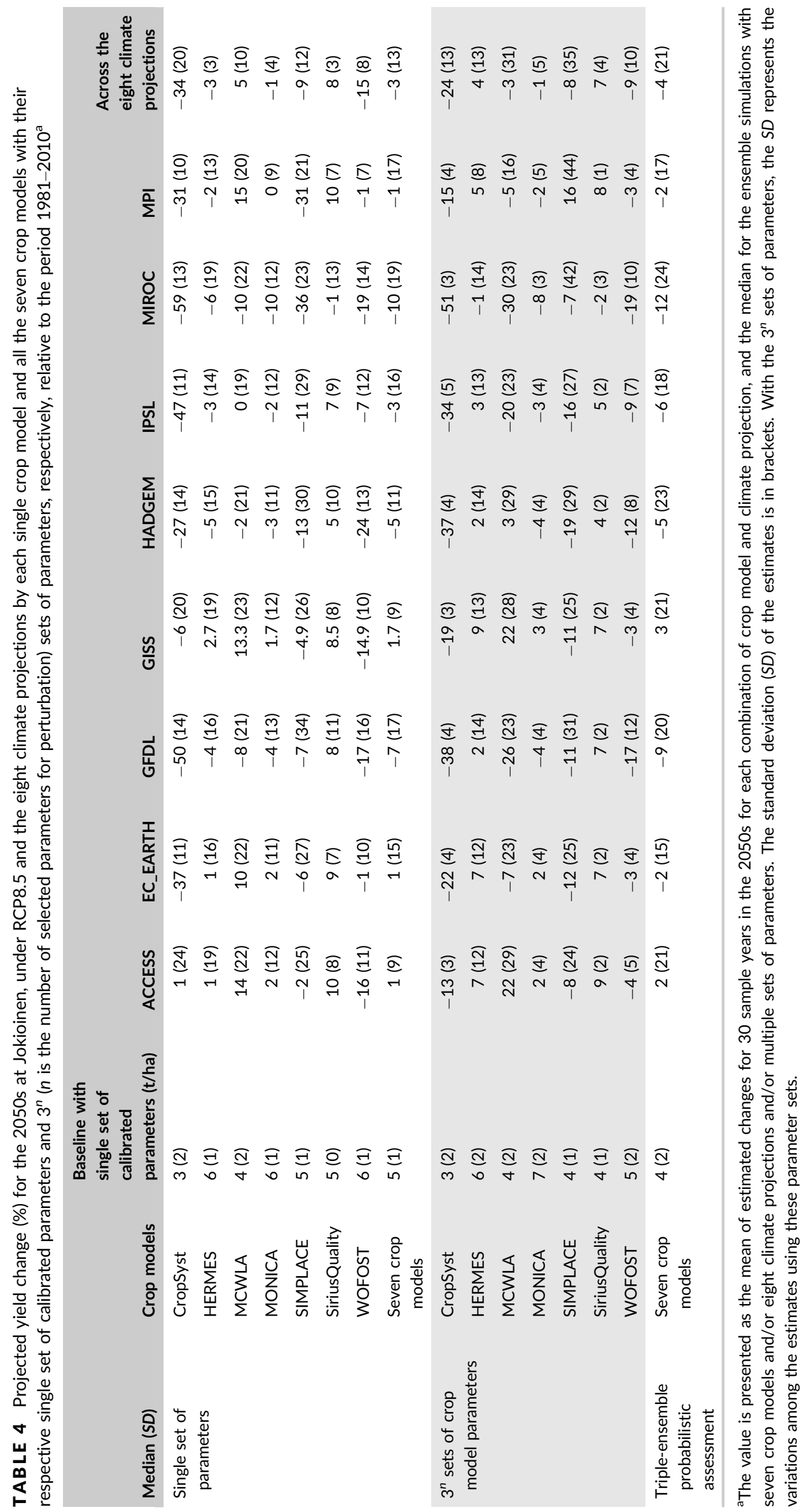




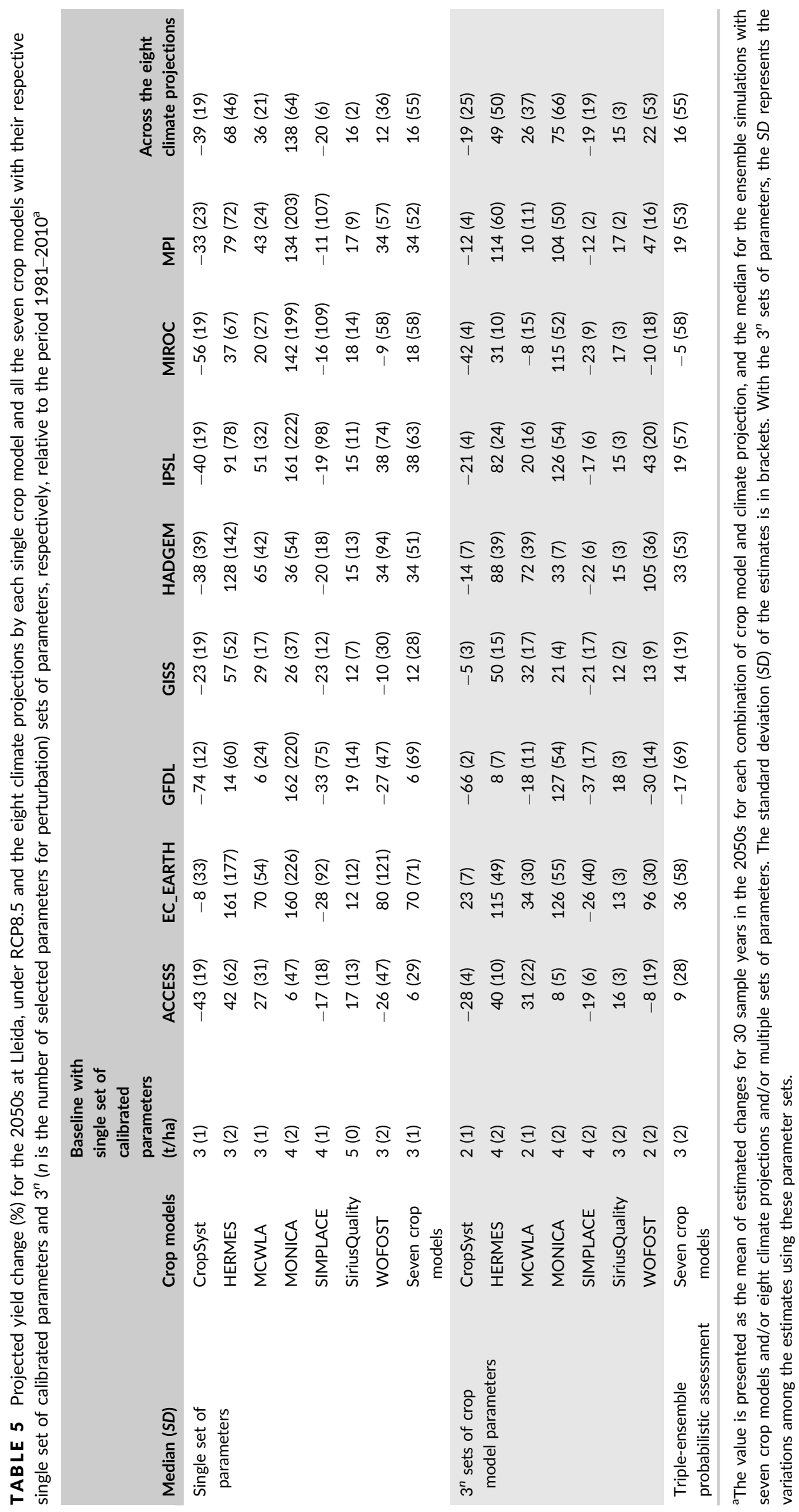




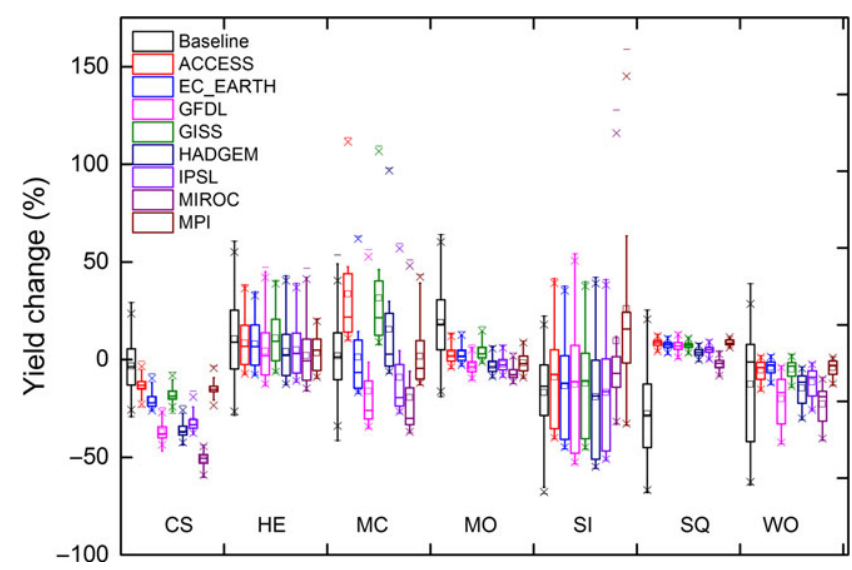

FIGURE 2 Box-Whisker plots (whisker: minimum and maximum; crosses: 0.01 and 0.99 percentiles; box: 0.25 quartile, median and 0.75 quartile; square: mean) of simulated yield changes at Jokioinen for the baseline (1981-2010) and the 2050s under eight climate projections (ACCESS, EC_EARTH, GFDL, GISS, HADGEM, IPSL, MIROC, MPI) by seven crop models (CS, HE, MC, MO, SI, SQ, WF) with their respective $3^{n}$ ( $n$ is the number of selected parameters for perturbation) sets of parameters. They were relative to the simulations with their respective single set of calibrated parameters for the baseline, and with $3^{n}$ sets of parameters for the 2050s. The boxplot reflects the interannual variation and parameter uncertainty with the number of samples being $3^{n}$ sets of parameters $\times 30$ years

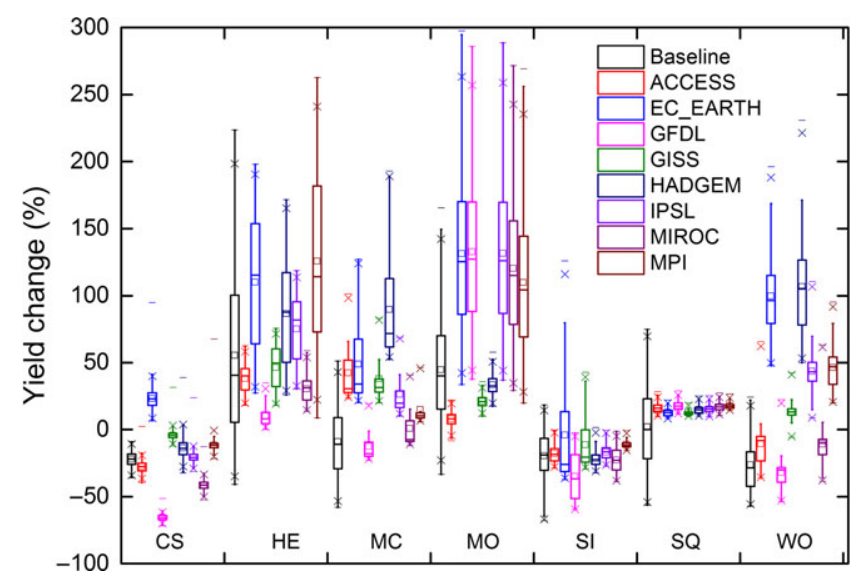

FIGURE 3 Box-Whisker plots (whisker: minimum and maximum; crosses: 0.01 and 0.99 percentiles; box: 0.25 quartile, median and 0.75 quartile; square: mean) of simulated yield changes at Lleida for the baseline (1981-2010) and the 2050s under eight climate projections (ACCESS, EC_EARTH, GFDL, GISS, HADGEM, IPSL, MIROC, MPI) by seven crop models (CS, HE, MC, MO, SI, SQ, WF) with their respective $3^{n}$ ( $n$ is the number of selected parameters for perturbation) sets of parameters. They were relative to the simulations with their respective single set of calibrated parameters for the baseline, and with $3^{n}$ sets of parameters for the 2050s. The boxplot reflects the interannual variation and parameter uncertainty with the number of samples being $3^{n}$ sets of parameters $\times 30$ years

Table 5) across the eight climate projections. The probability of decreasing yield (defined as a share of projections among all crop models with their respective $3^{n}$ sets of perturbed parameters) in the
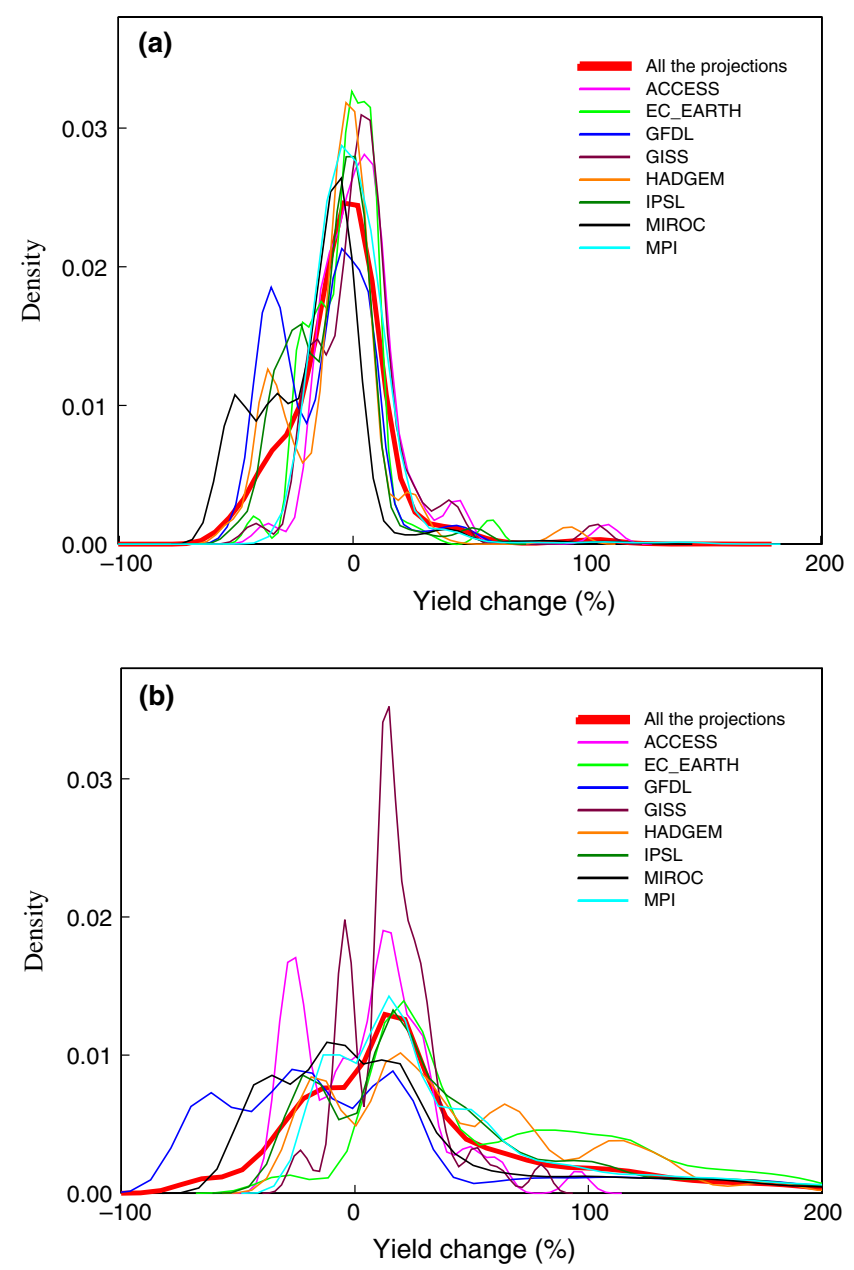

FIGURE 4 Probability density function of projected yield changes for the 2050s under eight climate projections. The projections of ACCESS, EC_EARTH, GFDL, GISS, HADGEM, IPSL, MIROC, MPI and all of them by seven crop models with their respective $3^{n}$ sets of parameters are displayed for Jokioinen (a) and Lleida (b), relative to their corresponding simulations for 1981-2010 with their respective $3^{n}$ sets of parameters

2050s relative to $1981-2010$ was projected to range from $42 \%$ to $89 \%$ at Jokioinen and from $4 \%$ to $56 \%$ at Lleida across the eight climate projections.

\section{5 | A triple-ensemble probabilistic assessment accounting for the uncertainties from model structure, model parameters and climate projections}

To account for the uncertainties in assessment of climate change impacts from model structure, model parameters and climate projections, a triple-ensemble probabilistic assessment approach was developed. It was based on the large number of crop model simulations (7 crop models $\times 3^{n}$ sets of model parameters $\times 8$ climate projections $\times 30$ years). All simulations were equally treated while constructing the ensemble. Based on the triple-ensemble probabilistic assessments, the results showed that in Jokioinen and Lleida, respectively, the median of simulated yield change was $-4 \%$ and $+16 \%$ in 
FIGURE 5 Comparisons of projected yield changes under eight climate projections at Jokioinen. Changes relative to 1981-2010 are displayed for climate projections by ACCESS, EC_EARTH, GFDL, GISS, HADGEM, IPSL, MIROC, MPI, and all of them by each single crop model and all seven models together with their single sets of calibrated parameters and $3^{n}$ sets of parameters respectively. The error bars represent the $S D$ of the corresponding estimates

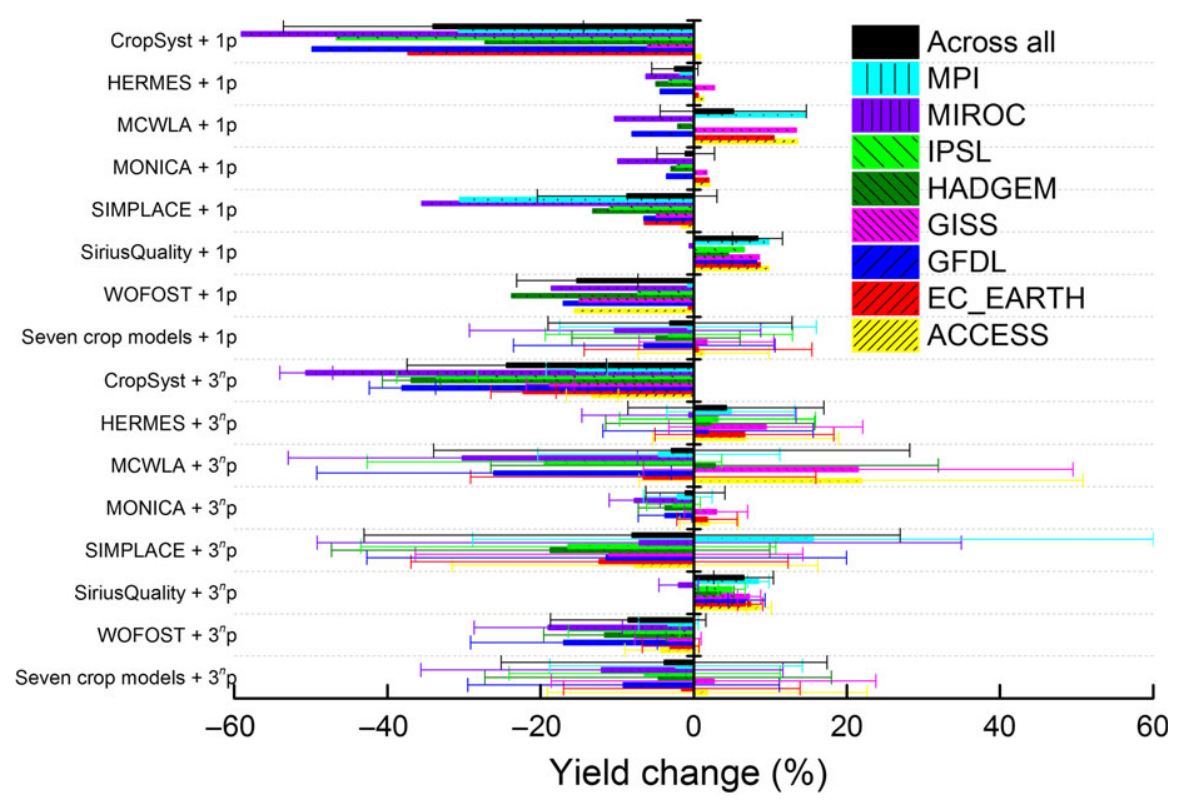

varied from $6 \%$ for the CropSyst model to $92 \%$ for the HERMES model at Jokioinen, and from $3 \%$ for the CropSyst model to $60 \%$ for the SiriusQuality model at Lleida. The contribution of climate projections varied from $5 \%$ for HERMES model to $90 \%$ for the CropSyst model at Jokioinen, and from $20 \%$ for the SIMPLACE model to $97 \%$ for the CropSyst model at Lleida. On average, the contribution of crop model parameters and climate projections was $42 \%$ and $46 \%$ at Jokioinen, and $24 \%$ and $59 \%$ at Lleida respectively (Figure 8 ). For all models but the SiriusQuality, the share of variance for model parameters at Jokioinen was higher than at Lleida. Four crop models, that is MCWLA, MONICA, SiriusQuality and WOFOST, resulted in very similar patterns of the shares of the different sources, whereas the three other models were distinctly different but each with a very special pattern. For the CropSyst, climate projections were overruling may be due to the parameter selection or/and too narrow parameter range. The HERMES behaved very differently at the two sites in terms of the shares may be due to too wide parameter range at Jokioinen.

\section{DISCUSSION}

\subsection{Accounting for uncertainties from multiple sources simultaneously using a super-ensemble probabilistic assessment}

Previous studies have investigated the uncertainty from one or two of the important sources in climate change impact assessments. This study investigated and compared, to our knowledge for the first time, the uncertainties from the three key sources together, that is crop model structure, crop model parameters and climate projections. We showed a large contribution from crop model structure, GCMs and crop model parameters to the total variance of ensemble output (Figures 7 and 8), warranting the need to further improve crop models and GCMs and to optimize model parameters. 


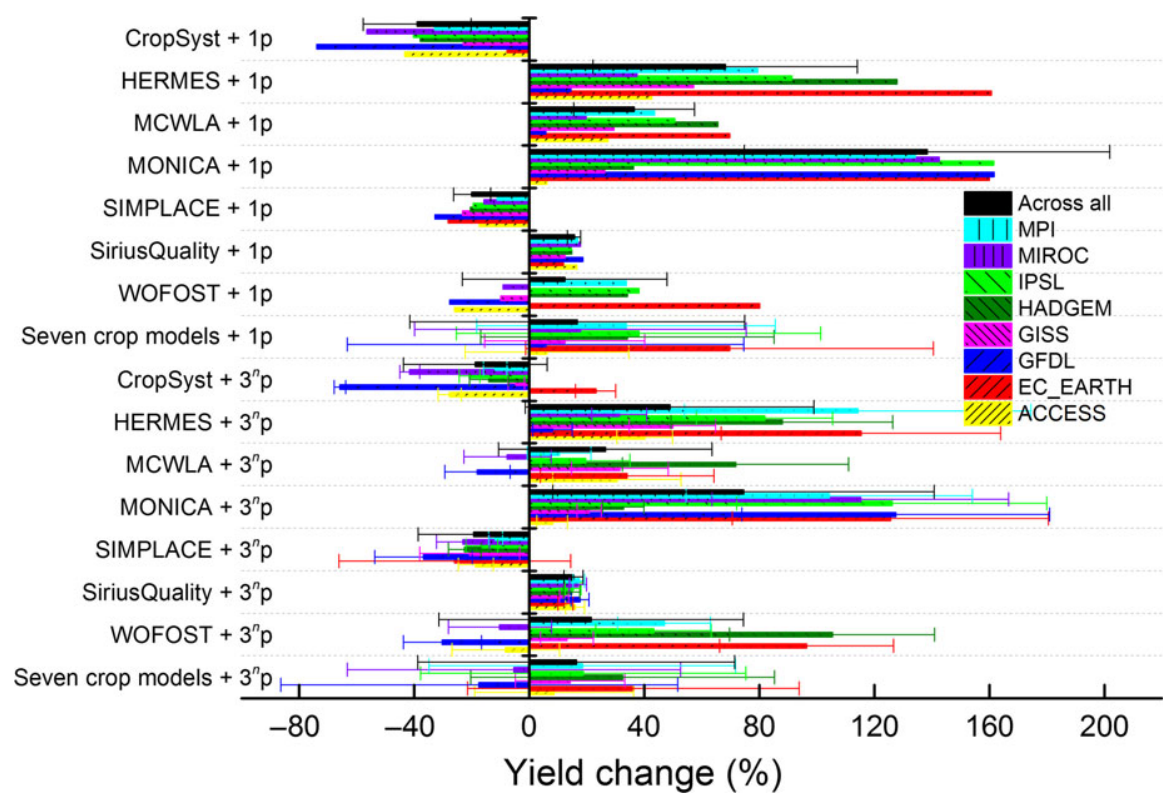

FIGURE 6 Comparisons of projected yield changes under eight climate projections at Lleida. Changes relative to 1981-2010 are displayed for climate projections by ACCESS, EC_EARTH, GFDL, GISS, HADGEM, IPSL, MIROC, MPI, and all of them by each single crop model and all seven models together with their single sets of calibrated parameters and $3^{n}$ sets of parameters respectively. The error bars represent the $S D$ of the corresponding estimates
Improvement of crop models and parameterization is hindered by both the shortage of high-quality experimental data, gaps in comprehensive experimental data sets as well as in full understanding of certain ecophysiological processes such as crop development, growth and grain formation and the various interactions between genotype, management and environment (Kersebaum et al., 2015). However, much more data exist than have actually been utilized to calibrate, and especially validate existing model structure and parameterization (Ainsworth \& Long, 2005; Medlyn et al., 2015; Vanuytrecht \& Thorburn, 2017). Up-to-date knowledge is often not exploited to improve model structure. For example for crop responses to $\mathrm{CO}_{2}$, more data are now becoming available, but have yet to be used in model improvement (Ainsworth \& Long, 2005; Medlyn et al., 2015; Vanuytrecht \& Thorburn, 2017). Uncertainty from GCMs structure and parameterization cannot easily be reduced either (Knutti \& Sedlacek, 2013).

To better assess climate change impact and inform adaptation, alternatively, sound approaches should be developed to account for the uncertainties in climate change impact assessment. Here, the triple-ensemble probabilistic assessment was developed was based on seven crop models, $3^{n}$ ( $n=7$ or 8 ) sets of crop model parameters and eight climate projections. The approach, presenting the results in a probabilistic framework, provides more comprehensive information for quantifying uncertainties in climate change impact assessments than the conventional approaches that are deterministic or only account for the uncertainties from one or two of the sources. Besides the uncertainties from the structure and parameters of the impact model and the GCM structure investigated here, those from other important sources, such as greenhouse gas emission scenarios, climate projection downscaling methods, climate model parameterization and initialization, could be further explored. Therefore, the triple-ensemble probabilistic assessment approach presented here can be further developed into 'a super-ensemble probabilistic assessment' by accounting for the uncertainties from more important uncertainty sources.

\subsection{Contribution of crop model structure, parameters and climate projections to uncertainties in climate change impact assessments}

We found the uncertainty from crop model structure was larger than that from downscaled climate projections (Figure 7). The results are supported by several previous studies on wheat (Asseng et al., 2013), maize (Bassu et al., 2014) and rice (Li et al., 2015). The reasons for the large uncertainty from crop model structure are complicated. For example these models have different modelling approaches for key crop development, growth, leaf area, photosynthesis and evapotranspiration, biomass accumulation and grain formation processes, as well as different temperature (Asseng et al., 2015; Wang et al., 2017) and $\mathrm{CO}_{2}$ relationships (Duranda et al., 2017; Hasegawa et al., 2017; Kersebaum \& Nendel, 2014; Vanuytrecht \& Thorburn, 2017). It is essential to improve the model descriptions of temperature and $\mathrm{CO}_{2}$ relationships and modelling approaches based on model comparison and evaluation and refinement utilizing suitable high-quality experimental data (Hasegawa et al., 2017; Wang et al., 2017).

The eight GCMs have different climatic sensitivity (Knutti \& Sedlacek, 2013), and the projected climate was quite different (Table 5). Despite extensive efforts to improve GCMs' performance in the simulation of various aspects of the climate system in the CMIP5 project, there are still substantial temperature biases and deficiencies in the GCMs' outputs (Knutti \& Sedlacek, 2013). Consequently, climate projections from GCMs need to be downscaled to local-scale climate scenarios. One of the commonly used downscaling techniques is based on a weather generator or/and change factors derived from GCMs (Barrow \& Semenov, 1995; Semenov \& Barrow, 1997; Wilks, 


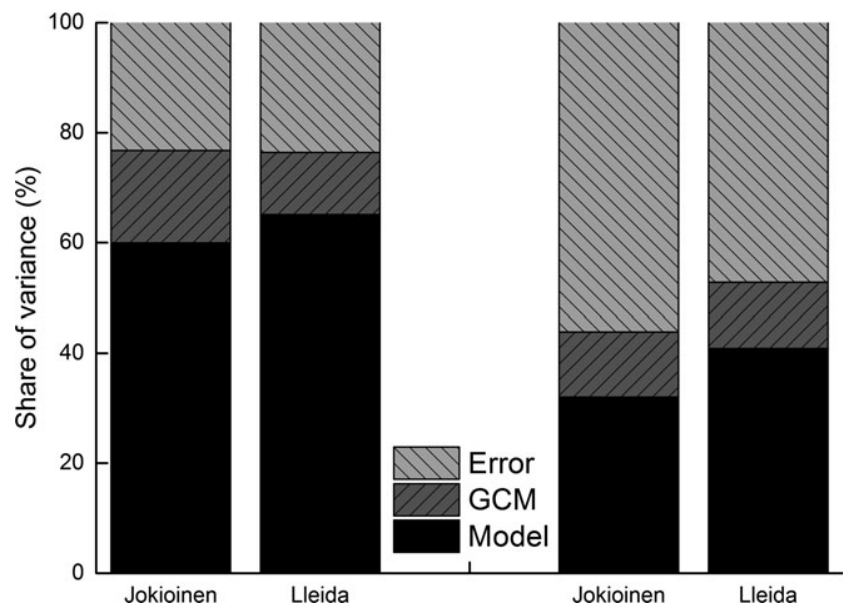

FIGURE 7 Share of variance by crop model structure and climate projections in the simulated barley yield changes. Calculations were carried out with seven crop models, eight climate projections, single set of calibrated parameters (left) or $3^{n}$ sets of parameters (right), for Jokioinen and Lleida respectively. The error variance is that which is neither due to crop model structure nor climate projections; hence, in the right two columns (with $3^{n}$ sets of parameters), the error variance includes the share of crop model parameters

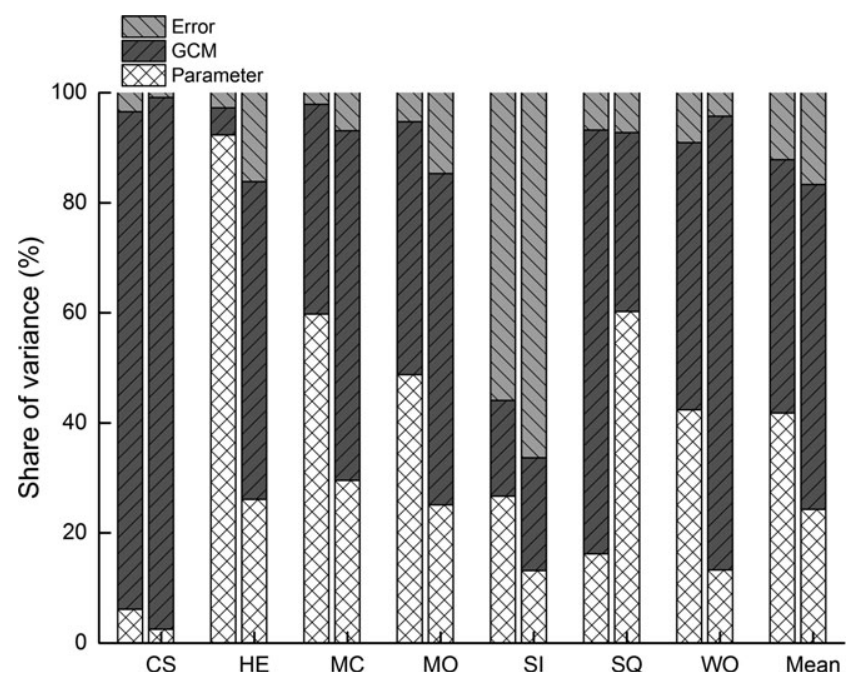

FIGURE 8 Share of variance by crop model parameters and climate projections in the climate change impact assessments for each crop model (CS, HE, MC, MO, SI, SQ, WO). For each crop model, the left column is for Jokioinen and the right column is for Lleida. The error variance is the share of variance which is neither due to crop model structure nor climate projections

1992). Downscaling techniques can bring additional uncertainty in climate scenarios (Wilby et al., 1998) and impact assessments; however, this uncertainty was not considered in this study. Possible reason for the smaller uncertainty from downscaled climate projections than from crop model structure could be that the differences among the climate projections were still not large enough to cause dramatic differences in response among the crop models, because crop response to climate change is not evident or dramatic if climate remains in the range below or above a threshold (Sánchez, Rasmussen, \& Porter, 2014).

We also found that the relative contributions of crop model parameters and climate projections to the total variance of ensemble output varied greatly among the seven crop models and between the two sites (Figure 8). The uncertainty from climate projections was on average larger than that from crop model parameters (Figure 8), which is supported by Tao, Yokozawa et al. (2009). The results suggest that more emphasis should be given to a representative preselection of GCMs for impact assessment and the selection approach should be further elaborated. It is important to select the GCMs that are capable of reproducing relevant weather patterns for the impact sector of interest. In addition, the development of the most likely probabilistic climate projection by weighting the performance of various GCMs in long-term hindcast simulations may be a promising solution (Das Bhowmik, Sharma, \& Sankarasubramanian, 2017).

The crop model parameters were perturbed based on the calibrated set of crop model parameters and their possible ranges. Since the value ranges of some parameters were large, the resultant simulated yields with $3^{n}$ sets of perturbed parameters had relatively large differences. The $3^{n}$ sets of parameters include all the possible combinations of seven or eight crop model parameters. The possible interdependencies among parameters were not taken into account. Nevertheless, this could only lead to a slight overestimation of uncertainties related to parameters because mismatch among the parameters could happen only in rare cases. It is difficult to quantify the overestimation of uncertainties due to the parameter mismatch because the biophysical consistency between these model parameters is not yet fully understood. In the future, better integrated efforts among plant physiologists, geneticists, breeders and crop modellers, which are based on more comprehensive datasets, will allow better coupling of genotype-phenotype modelling and consequently will provide more insight into plausible uncertainty space. For climate projections in contrast, projected changes in different weather variables are physically consistent. In addition, the uncertainties from crop model parameters reflected not only the uncertainties in biophysical processes, but also the effects of differing traits for cultivars, which to some extent reflect uncertainty in assumptions about genetic variations of the traits currently or in the near future. The crop model parameters that were identified as influential by the different crop modelling groups differ among the models, as do their ranges of variation, which can contribute to the uncertainties from crop model structures and parameters, too. For example the special patterns of the shares of the different sources for the CropSyst and HERMES (Figure 8) may be due to too narrow and too wide parameter range respectively. The plausible range of parameters for a specific environment or/and cultivar should be better elaborated to constrain model parameters more rigorously in climate change impact assessment. More elaborate multipleenvironment trial data and some recently developed, advanced optimization techniques for model parameters, such as the Bayesian probability inversion and a Markov chain Monte Carlo (MCMC) 
technique (lizumi et al., 2009; Tao, Zhang et al., 2009), should be useful to explore the optimal and biophysically sound crop model parameters for a specific environment. The relative contribution of crop model structure and parameters to the total variance of ensemble output could not be rigorously and directly compared using ANOVA in the settings of this study because the model parameter set is specific to each crop model and cannot be applied by another crop model. Nevertheless, the large deviations among the different crop models (Figures 2 and 3) suggest that uncertainty from model structure may generally be larger than that from model parameters, particularly when crop models have been well calibrated. This is supported by a recent study of Zhang et al. (2017).

Our study suggests that the number of crop models and climate projections, as well as the individual crop model ensemble members, should be more rigorously selected, based on the characteristics of the study area, the purpose of the study, and the advantages of a certain model. Given the highly localized, management-specific nature of cropping systems, crop model selection and a plausible range of parameters should be carefully justified for a specific environment. This point is supported by several previous studies, which show that some crop models perform well in one environment but not in another environment, and vice versa (Asseng et al., 2013; Bassu et al., 2014; Huang, Huang, Yu, Ni, \& Yu, 2017; Li et al., 2015). Many crop models are developed for a specific focus and spatial scale, consequently strong in some aspects but weak in others; these should be kept in mind in the selection of crop model for a specific task. In comparison to crop models and climate projections, crop model parameterization contributes relatively little to overall uncertainty. With this information in mind, model users can decide where to put the most effort when preparing or choosing models or parameters for impact analyses.

\subsection{Reducing and quantifying uncertainties in climate change impact assessment}

Several previous studies have indicated that crop models have the largest uncertainties under extreme climatic conditions (Asseng et al., 2015; Wang et al., 2017; Zhang \& Tao, 2013). Understanding of the impacts of extreme climates on the processes of plant development, growth and grain formation is still relatively poor (e.g. Asseng et al., 2015; Lesk, Rowhani, \& Ramankutty, 2016; Lobell et al., 2013). Therefore, model equations and model parameters should be further elaborated, for example by improving the temperature and $\mathrm{CO}_{2}$ response functions in models using high-quality experimental data under controlled environmental conditions (Asseng et al., 2015; Duranda et al., 2017; Gabaldón-Leal et al., 2016; Maiorano et al., 2017; Rötter, Carter et al., 2011; Wang et al., 2017). The model description of $\mathrm{CO}_{2}$ relationships is another key uncertainty source for future yield prediction needed to be reduced (Duranda et al., 2017; Hasegawa et al., 2017; Vanuytrecht \& Thorburn, 2017). With the free-air $\mathrm{CO}_{2}$ enrichment (FACE) experimental data, a recent study showed that many maize models could not simulate the very low soil water content at anthesis and the increase in soil water and grain number brought about by elevated $\mathrm{CO}_{2}$ concentration under dry conditions, model improvement with respect to simulating transpiration water use and its impact on water status during the kernel-set phase was thereby suggested (Duranda et al., 2017). Another study showed that yield prediction in response to elevated $\mathrm{CO}_{2}$ concentration varied significantly among 16 rice models. The variation was not associated with model structure or magnitude of photosynthetic response to elevated $\mathrm{CO}_{2}$ concentration, but was significantly associated with the predictions of leaf area. The improvement on model simulation of leaf area and $\mathrm{CO}_{2} \times$ Nitrogen interaction was thereby suggested (Hasegawa et al., 2017).

Besides, these impact uncertainties can be better quantified through use of the super-ensemble probabilistic assessment approaches than by conventional approaches (Wallach et al., 2016), because the former provide better estimates and more information, accelerating the communication of the results with stakeholders and policy-makers in a probabilistic framework. Previous studies suggest that the median value of a multimodel ensemble was more accurate in simulating the crop temperature response and yields than any single model (Asseng et al., 2013; Martre et al., 2015). When adopting the median value, special attention should be paid to the cases when half of the impact models provide one impact sign and the rest provide the opposite sign. Our results suggest the use of superensemble probabilistic assessments that account for the uncertainties from multiple important sources should provide more useful information, better quantification of the uncertainties, and consequently better communication of the estimates. It should be kept in mind that the focus of this paper was to investigate the uncertainty from crop model structure, parameters and climate projections in climate impact assessment; with few exceptions such as future cultivar traits adaptation options were not taken into account. This is sound because these virtual cultivars can be fairly evaluated under a wide range of reasonable sowing dates and agronomic management practices including those applied in this study. A wide spectrum of adaptation options can be incorporated in further studies. However, elaboration of the super-ensemble probabilistic assessment demands considerable computing power and resources, particularly for climate impact assessment at a regional or global scale.

\section{ACKNOWLEDGEMENTS}

This study was carried out in the context of CropM within the FACCE-MACSUR knowledge hub (031A103B). FT and TP were supported by the Ministry of Agriculture and Forestry (FACCE-MACSUR) and by the Academy of Finland, the NORFASYS project (decision 268277 and 292944) and PLUMES project (decision. 277403 and 292836). RPR was supported by the German Federal Ministry of Education and Research via the 'Limpopo Living Landscapes' project within the SPACES programme (grant number 01LL1304A) and by the IMPAC^3 project funded by the German Federal Ministry of Education and Research (FKZ 031A351A). MIM, LR and MRR (CEIGRAM-UPM) were supported by MULCLIVAR CGL2012-38923-C02-02 from MINECO. HH, TG and FE were 
financially supported by the German Federal Ministry of Food and Agriculture (BMEL) through the Federal Office for Agriculture and Food (BLE), (2851ERA01J), and thank Andreas Enders and Gunther Krauss (INRES, University of Bonn) for support. KCK and CN were supported by German Ministry of Education and Research (BMBF), 031B0039C. AD and PM were supported by the European Union's Seventh Framework Programme (FP7/2007-2013; grant no. FP7613556) and the FACCE-MACSUR project (031A103B) through the metaprogramme on Adaptation of Agriculture and Forests to Climate Change (AAFCC) of the French National Institute for Agricultural Research (INRA). The work of AHS was carried out under the FACCE-JPI project ClimBar (Academy of Finland decision 284987). M.B and R.F were funded by JPI FACCE MACSUR2 through the Italian Ministry for Agricultural, Food, and Forestry Policies. Rothamsted Research receives grant-aided support from the Biotechnology and Biological Sciences Research Council (BBSRC) Designing Future Wheat project (BB/P016855/1). Financial support from these projects is gratefully acknowledged. We also acknowledge greatly the anonymous referees for their valuable comments on the early version of this manuscript.

\section{ORCID}

Fulu Tao iD http://orcid.org/0000-0001-8342-077X

Davide Cammarano iD http://orcid.org/0000-0003-0918-550X

\section{REFERENCES}

Ainsworth, E. A., \& Long, S. P. (2005). What have we learned from 15 years of free-air $\mathrm{CO}_{2}$ enrichment (FACE)? A meta-analytic review of the responses of photosynthesis, canopy properties and plant production to rising $\mathrm{CO}_{2}$. New Phytologist, 165, 351-372.

Angulo, C., Rötter, R., Lock, R., Enders, A., Fronzek, S., \& Ewert, F. (2013). Implication of crop model calibration strategies for assessing regional impacts of climate change in Europe. Agricultural and Forest Meteorology, 170, 32-46.

Asseng, S., Ewert, F., Martre, P., Rötter, R. P., Lobell, D. B., Cammarano, D., ... Reynolds, M. P. (2015). Rising temperatures reduce global wheat production. Nature Climate Change, 5, 143-147.

Asseng, S., Ewert, F., Rosenzweig, C., Jones, J. W., Hatfield, J. L., Ruane, A. C., ... Brisson, N. (2013). Uncertainty in simulating wheat yields under climate change. Nature Climate Change, 3, 827-832.

Barrow, E. M., \& Semenov, M. A. (1995). Climate change scenarios with high spatial and temporal resolution for agricultural applications. Forestry, 68, 349-360.

Bassu, S., Brisson, N., Durand, J. L., Boote, K., Lizaso, J., Jones, J. W., ... Basso, B. (2014). How do various maize crop models vary in their responses to climate change factors? Global Change Biology, 20, 2301-2320.

Boogaard, H., \& Kroes, J. (1998). Leaching of nitrogen and phosphorus from rural areas to surface waters in the Netherlands. Nutrient Cycling in Agroecosystems, 50, 321-324.

Cantero-Martinez, C., Angas, P., \& Lampurlanes, J. (2003). Growth, yield and waterproductivity of barley (Hordeum vulgare L.) affected by tillage and $\mathrm{N}$ fertilization in Mediterranean semiarid, rainfed conditions of Spain. Field Crops Research, 84, 341-357.
Castañeda-Vera, A., Leffelaar, P. A., Álvaro-Fuentes, J., Cantero-Martínez, C., \& Mínguez, M. I. (2015). Selecting crop models for decision making in wheat insurance. European Journal of Agronomy, 68, 98-116.

Challinor, A. J., Smith, M. S., \& Thornton, P. (2013). Use of agro-climate ensembles for quantifying uncertainty and informing adaptation. Agricultural and Forest Meteorology, 170, 2-7.

Challinor, A. J., Wheeler, T., Hemming, D., \& Upadhyaya, H. D. (2009). Ensemble yield simulations: Crop and climate uncertainties, sensitivity to temperature and genotypic adaptation to climate change. Climate Research, 38, 117-127.

Das Bhowmik, R., Sharma, A., \& Sankarasubramanian, A. (2017). Reducing model structural uncertainty in climate model projections - A rankbased model combination approach. Journal of Climate, https://doi. org/10.1175/JCLI-D-17-0225.1

Dufresne, J. -L., Foujols, M. -A., Denvil, S., Caubel, A., Marti, O., Aumont, O., ... Vuichard, N. (2013). Climate change projections using the IPSL-CM5 earth system model: From CMIP3 to CMIP5. Climate Dynamics, 40(9-10), 2123-2165.

Dunne, J. P., John, J. G., Shevliakova, E., Stouffer, R. J., Krasting, J. P., Malyshev, S. L., ... Dunne, K. A. (2013). GFDL's ESM2 global coupled climate-carbon earth system models. Part II: Carbon system formulation and baseline simulation characteristics. Journal of Climate, 26, 2247-2267.

Duranda, J. L., Delusca, K., Boote, K., Lizaso, J., Manderschei, R., Weigel, H.J. ... Anapalli, S. (2017). How accurately do maize crop models simulate the interactions of atmospheric $\mathrm{CO}_{2}$ concentration levels with limited water supply on water use and yield? European Journal of Agronomy, in press. https://doi.org/10.1016/j.eja.2017.01.002.

Ewert, F., Rötter, R. P., Bindi, M., Webber, H., Trnka, M., Kersebaum, K.C., ... Asseng, S. (2015). Crop modelling for integrated assessment of risk to food production from climate change. Environmental Modelling \& Software, 72, 287-303.

Gabaldón-Leal, C., Webber, H., Otegui, M. E., Slafer, G. A., Ordóñez, R. A., Gaiser, T., ... Ewert, F. (2016). Modelling the impact of heat stress on maize yield formation. Field Crops Research, 198, 226-237.

Godfray, H. C. J., Beddington, J. R., Crute, I. R., Haddad, L., Lawrence, D., Muir, J. F., ... Toulmin, C. (2010). Food security: The challenge of feeding 9 billion people. Science, 327, 812-818.

Hasegawa, T., Li, T., Yin, X., Zhu, Y., Boote, K., Baker, J., ... Fumoto, T. (2017). Causes of variation among rice models in yield response to $\mathrm{CO} 2$ examined with Free-Air $\mathrm{CO} 2$ Enrichment and growth chamber experiments. Scientific Reports, 7, 14858 in press. https://doi.org/10. 1038/s41598-017-13582-y

Hazeleger, W., Wang, X., Severijns, C., Ştefănescu, S., Bintanja, R., Sterl, A., ... Van Noije, T. (2012). EC-Earth V2.2: Description and validation of a new seamless earth system prediction model. Climate Dynamics, 39, 2611-2629.

Huang, X., Huang, G., Yu, C., Ni, S., \& Yu, L. (2017). A multiple crop model ensemble for improving broad-scale yield prediction using Bayesian model averaging. Field Crops Research, 211, 114-124.

lizumi, T., Yokozawa, M., \& Nishimori, M. (2009). Parameter estimation and uncertainty analysis of a large-scale crop model for paddy rice: Application of a Bayesian approach. Agricultural and Forest Meteorology, 149, 333-348.

Jones, C. D., Hughes, J. K., Bellouin, N., Hardiman, S. C., Jones, G. S., Knight, J., ... Boo, K. O. (2011). The HadGEM2-ES implementation of CMIP5 centennial simulations. Geoscientific Model Development, 4, $543-570$

Kersebaum, K. (2007). Modelling nitrogen dynamics in soil-crop systems with HERMES. Nutrient Cycling in Agroecosystems, 77, 39-52.

Kersebaum, K. C., Boote, K. J., Jorgenson, J. S., Nendel, C., Bindi, M., Frühauf, C. ... Rötter, R.P. (2015). Analysis and classification of data sets for calibration and validation of agro-ecosystem models. Environmental Modelling \& Software, 72, 402-417. 
Kersebaum, K., \& Nendel, C. (2014). Site-specific impacts of climate change on wheat production across regions of Germany using different $\mathrm{CO}_{2}$ response functions. European Journal of Agronomy, 52, 22 32.

Knutti, R., \& Sedlacek, J. (2013). Robustness and uncertainties in the new CMIP5 climate model projections. Nature Climate Change, 3, 369373.

Lesk, C., Rowhani, P., \& Ramankutty, N. (2016). Influence of extreme weather disasters on global crop production. Nature, 529, 84-87.

Li, T., Hasegawa, T., Yin, X., Zhu, Y., Boote, K., Adam, M., ... Gaydon, D. (2015). Uncertainties in predicting rice yield by current crop models under a wide range of climatic conditions. Global Change Biology, 21, 1328-1341.

Lobell, D. B., \& Burke, M. B. (2008). Why are agricultural impacts of climate change so uncertain? The importance of temperature relative to precipitation. Environment Research Letter, 3, 034007.

Lobell, D. B., Hammer, G. L., McLean, G., Messina, C., Roberts, M. J., \& Schlenker, W. (2013). The critical role of extreme heat for maize. Nature Climate Change, 3, 497-501.

Maiorano, A., Martre, P., Asseng, S., Ewert, F., Müller, C., Rötter, R. P., .. . Alderman, P. D. (2017). Crop model improvement reduces the uncertainty of the response to temperature of multi-model ensembles. Field Crops Research, 202, 5-20.

Martre, P., Jamieson, P., Semenov, M. A., Zyskowski, R. F., Porter, J. R., \& Triboi, E. (2006). Modelling protein content and composition in relation to crop nitrogen dynamics for wheat. European Journal of Agronomy, 25, 138-154.

Martre, P., Wallach, D., Asseng, S., Ewert, F., Jones, J. W., Rötter, R. P., ... Hatfield, J. L. (2015). Multimodel ensembles of wheat growth: Many models are better than one. Global Change Biology, 21, 911925.

Medlyn, B. E., Zaehle, S., De Kauwe, M. G., Walker, A. P., Dietze, M. C., Hanson, P. J., ... Prentice, I. C. (2015). Using ecosystem experiments to improve vegetation models. Nature Climate Change, 5, 528-534.

Nazarenko, L., Schmidt, G. A., Miller, R. L., Tausnev, N., Kelley, M., Ruedy, R., ... Bleck, R. (2015). Future climate change under RCP emission scenarios with GISS Model E2. Journal of Advances in Modeling Earth Systems, 7, 244-267.

Nendel, C., Berg, M., Kersebaum, K. C., Mirschel, W., Specka, X., Wegehenkel, M., ... Wieland, R. (2011). The MONICA model: Testing predictability for crop growth, soil moisture and nitrogen dynamics. Ecological Modelling, 222, 1614-1625.

Palosuo, T., Kersebaum, K. C., Angulo, C., Hlavinka, P., Moriondo, M., Olesen, J. E., ... Trnka, M. (2011). Simulation of winter wheat yield and its variability in different climates of Europe: A comparison of eight crop growth models. European Journal of Agronomy, 35, 103114.

Pirttioja, N., Carter, T. R., Fronzek, S., Bindi, M., Hoffmann, H., Palosuo, T., ... Rötter, R. P. (2015). A crop model ensemble analysis of temperature and precipitation effects on wheat yield across a European transect using impact response surfaces. Climate Research, 65, 87105.

Porter, J. R., Xie, L., Challinor, A., Cochrane, K., Howden, S. M., Iqbal, M. M., ... Garrett, K. (2014). Food security and food production systems. In C. B. Field, V. R. Barros, D. J. Dokken, K. J. Mach, M. D. Mastrandrea, T. E. Bilir, M. Chatterjee, K. L. Ebi, Y. O. Estrada, R. C. Genova, B. Girma, E. S. Kissel, A. N. Levy, S. MacCracken \& P. R. Mastrandrea (Eds.), Climate change 2014: Impacts, adaptation and vulnerability. Contribution of working group II to the fifth assessment report of the intergovernmental panel on climate change (pp. 485-533). Cambridge, UK: Cambridge University Press.

Raddatz, T. J., Reick, C. H., Knorr, W., Kattge, J., Roeckner, E., Schnur, R., ... Jungclaus, J. (2007). Will the tropical land biosphere dominate the climate-carbon cycle feedback during the twenty-first century? Climate Dynamics, 29, 565-574.
Rashid, H., Hirst, A., \& Dix, M. (2013). Atmospheric circulation features in the ACCESS model simulations for CMIP5: Historical simulation and future projections. Australian Meteorological and Oceanographic Journal, 63, 145-160.

Rosenzweig, C., Elliott, J., Deryng, D., Ruane, A. C., Müller, C., Arneth, A., ... Jones, J. W. (2014). Assessing agricultural risks of climate change in the twenty-first century in a global gridded crop model intercomparison. Proceedings of the National Academy of Sciences of the United States of America, 111, 3268-3273.

Rosenzweig, C., Jones, J. W., Hatfield, J. L., Ruane, A. C., Boote, K. J., Thorburn, P., ... Ewert, F. (2013). The agricultural model intercomparison and improvement project (AgMIP). Agricultural and Forest Meteorology, 170, 166-182.

Rötter, R. P. (2014). Robust uncertainty. Nature Climate Change, 4, 251 252.

Rötter, R. P., Carter, T. R., Olesen, J. E., \& Porter, J. R. (2011). Crop-climate models need an overhaul. Nature Climate Change, 1, 175-177.

Rötter, R. P., Palosuo, T., Kersebaum, K.-C., Angulo, C., Bindi, M., Ewert, F., ... Trnka, M. (2012). Simulation of spring barley yield in different climatic zones of Northern and Central Europe: A comparison of nine crop growth models. Field Crops Research, 133, 23-36.

Rötter, R. P., Palosuo, T., Pirttioja, N. K., Dubrovsky, M., Salo, T., Fronzek, S., ... Carter, T. R. (2011). What would happen to barley production in Finland if global warming exceeded $4^{\circ} \mathrm{C}$ ? A model-based assessment. European Journal of Agronomy, 35, 205-214.

Salo, T., Palosuo, T., Kersebaum, K. C., Nendel, C., Angulo, C., Ewert, F., ... Rötter, R. P. (2016). Comparing the performance of 11 crop simulation models in predicting yield response to nitrogen fertilization. Journal Agricultural Science, 154, 1218-1240.

Sánchez, B., Rasmussen, A., \& Porter, J. R. (2014). Temperatures and the growth and development of maize and rice: A review. Global Change Biology, 20, 408-417.

Semenov, M. A., \& Barrow, E. M. (1997). Use of a stochastic weather generator in the development of climate change scenarios. Climatic Change, 35, 397-414.

Semenov, M. A., \& Stratonovitch, P. (2015). Adapting wheat ideotypes for climate change: Accounting for uncertainties in CMIP5 climate projections. Climate Research, 65, 123-139.

Stockle, C., Donatelli, M., \& Nelson, R. (2003). CropSyst, a cropping systems simulation model. European Journal of Agronomy, 18, 289-307.

Tao, F., Hayashi, Y., Zhang, Z., Sakamoto, T., \& Yokozawa, M. (2008). Global warming, rice production, and water use in China: Developing a probabilistic assessment. Agricultural and Forest Meteorology, 148, 94-110.

Tao, F., Rötter, R., Palosuo, T., Díaz-Ambrona, C. G. H., Mínguez-Tudela, M. I., Semenov, M., ... Schulman, A. H. (2016). Designing future barley ideotypes using a crop model ensemble. European Journal Agronomy, 82, 144-162.

Tao, F., Yokozawa, M., \& Zhang, Z. (2009). Modeling the impacts of weather and climate variability on crop productivity over a large area: A new process-based model development, optimization, and uncertainties analysis. Agricultural and Forest Meteorology, 149, 831-850.

Tao, F., Zhang, Z., Liu, J., \& Yokozawa, M. (2009). Modeling the impacts of weather and climate variability on crop productivity over a large area: A new super-ensemble based probability projection. Agricultural and Forest Meteorology, 149, 1266-1278.

Vanuytrecht, E., \& Thorburn, P. J. (2017). Responses to atmospheric $\mathrm{CO}_{2}$ concentrations in crop simulation models: A review of current simple and semicomplex representations and options for model development. Global Change Biology, 23, 1806-1820.

Wallach, D., Mearns, L. O., Ruane, A. C., Rötter, R. P., \& Asseng, S. (2016). Lessons from climate modeling on the design and use of ensembles for crop modeling. Climatic Change, 139, 551-564.

Wallach, D., Nissanka, S. P., Karunaratne, A. S., Weerakoon, W. M. W., Thorburn, P. J., Boote, K. J., \& Jones, J. W. (2017). Accounting for 
both parameter and model structure uncertainty in crop model predictions of phenology: A case study on rice. European Journal of Agronomy, 88, 53-62.

Wang, E., Martre, P., Zhao, Z., Ewert, F., Maiorano, A., Rötter, R. P., ... Asseng, S. (2017). The uncertainty of crop yield projections is reduced by improved temperature response functions. Nature Plants, 3, 833. Article number: 17102.

Watanabe, S., Hajima, T., Sudo, K., Nagashima, T., Takemura, T., Okajima, H., ... Kawamiya, M. (2011). MIROC-ESM 2010: Model description and basic results of CMIP5-20c3 m experiments. Geoscientific Model Development, 4, 845-872.

White, J. W., Hoogenboom, G., Kimball, B. A., \& Walla, G. W. (2011). Methodologies for simulating impacts of climate change on crop production. Field Crops Research, 124, 357-368.

Wilby, R. L., Wigley, T. M. L., Conway, D., Jones, P. D., Hewiston, B. C., Main, J., \& Wilks, D. S. (1998). Statistical downscaling of general circulation model output: A comparison of methods. Water Resources Research, 34, 2995-3008.

Wilks, D. S. (1992). Adapting stochastic weather generation algorithms for climate changes studies. Climatic Change, 22, 67-84.

Zhang, S., \& Tao, F. (2013). Modeling the response of rice phenology to climate change and variability in different climatic zones: comparisons of five models. European Journal of Agronomy, 4, 165-176.
Zhang, S., Tao, F., \& Zhang, Z. (2017). Uncertainty from model structure is larger than that from model parameters in simulating rice phenology in China. European Journal of Agronomy, 87, 30-39.

\section{SUPPORTING INFORMATION}

Additional Supporting Information may be found online in the supporting information tab for this article.

How to cite this article: Tao F, Rötter RP, Palosuo T, et al. Contribution of crop model structure, parameters and climate projections to uncertainty in climate change impact assessments. Glob Change Biol. 2018;24:1291-1307. https://doi.org/10.1111/gcb.14019 